\title{
Madres, madrinas y vecinas. Neuroendocrinología del comportamiento maternal en el ratón
}

\author{
Hugo SALAIS LÓPEZ \\ salais@uji.es \\ ANA MARTín SÁNCHEZ \\ Ana.Martin@uv.es \\ Marcos Otero García \\ Marcos.Otero@uv.es \\ FERNANDO MARTíNEZ GARCÍA \\ femartin@uji.es
}

\section{Resumen}

La conducta maternal es algo más que la nutrición y protección de la descendencia. En humanos y otras especies, la desatención maternal provoca cambios epigenéticos que reducen la resistencia al estrés y perpetúan la desatención maternal. El estudio del sustrato neural de este comportamiento ayudará a romper este círculo vicioso y a promover la salud física y mental de futuras generaciones. Hemos investigado en el ratón cuáles son los factores clave que desencadenan la fiera defensa de las crías por parte de sus madres, la agresión maternal. Esta conducta debe estar promovida por señales hormonales de la gestación, puesto que las madrinas o comadres, hembras que han colaborado en el cuidado de las crías pero no han experimentado la maternidad, no son agresivas. Centrando nuestra atención sobre las hormonas de la maternidad, hemos caracterizado el efecto de la prolactina en el encéfalo. Los resultados indican que durante la gestación se produce una activación drástica, mediada por señales lactogénicas, de todo el cerebro sociosexual, incluyendo los núcleos responsables de la agresión. Esta activación continúa durante la lactancia, sustentada por los elevados niveles de prolactina propios de este periodo. Por último, hemos identificado las neuronas que generan circuitos centrales ricos en vasopresina y oxitocina, dos neuropéptidos clave en la regulación del comportamiento maternal. Neuronas que expresan ambos neuropéptidos, situadas entre la región amigdalina y el hipotálamo preóptico, parecen proyectar a centros responsables de la ansiedad (amígdala central) y la motivación (núcleo accumbens). Su modulación explicaría la reducción de la ansiedad durante la maternidad, que permite respuestas como la agresión maternal, así como el incremento de la motivación hacia las crías y su cuidado.

Palabras clave: comportamiento maternal, agresión maternal, prolactina, oxitocina, vasopresina, cerebro sociosexual. 


\section{Abstract}

Maternal behaviour is not limited to the nourishment and protection of the offspring. In humans as in other species, maternal neglect induces epigenetic modifications that compromise resilience to stress and perpetuate inattention. The study of the neural substrate of this behaviour will help to break this vicious cycle and to promote physical and mental health of future generations. We have explored which are the key factors, in the mouse, that trigger in the mother the fierce defence of the pups from external threats, maternal aggression. This behaviour must be promoted by the hormonal cues of the maternal period, since godmothers, females that shared pup care with the mother, but have not undergone motherhood, are not aggressive. Focusing on important hormonal signals during this period, we have characterised the central effect of prolactin, the maternal hormone. Our results indicate that, during pregnancy, lactogenic signals exert a drastic activation of the sociosexual brain, including centres responsible for aggression. These activation continues during lactation, hosted by the elevated levels of prolactin during this period. Lastly, we have identified the neurons generating central circuits rich in vasopressin and oxytocin, two neuropeptides with a key role in the regulation of maternal behaviour. Neurons expressing both neuropeptides and located between the amygdaloid region and preoptic hypothalamus, project to neural centres responsible for anxiety behaviour (central tonsil) and motivation (nucleus accumbens). The modulation of these sites would explain the reduction of anxiety during the motherhood, which ensures behaviours like maternal aggression, as well as the increase in pup-directed motivated behaviours.

Keywords: maternal care, maternal aggression, prolactin, oxytocin, vasopressin, sociosexual brain.

\section{Introducción}

El comportamiento parental se define como una colección de conductas expresadas por uno o ambos progenitores (aunque en muchas especies solo hay comportamiento maternal) dirigidas a la atención de las necesidades básicas de las crías, principalmente su alimentación, termorregulación y protección. Este carácter surge evolutivamente como una estrategia compleja y costosa pero muy efectiva para garantizar la supervivencia de la descendencia, especialmente cuando ésta es altricial, es decir, cuando nace, como en la especie humana, con un desarrollo somático incompleto y es por tanto incapaz de valerse por sí misma en el periodo postnatal (Numan e Insel, 2003).

El comportamiento parental es, pues, un mecanismo esencial para la supervivencia de las crías, pero sus funciones parecen ir más allá. Existe evidencia creciente de que un buen cuidado parental tiene un impacto beneficioso en la salud física y mental de la descendencia. Se ha comprobado en roedores como madres que cuidan satisfactoriamente de sus crías les transmiten, por medios epigenéticos, la capacidad de tolerar mejor el estrés y sus efectos negativos sobre el organismo (Meaney, 2001). Estableciendo una comparación con el ser humano, se ha determinado también como diferentes formas de desatención y maltrato parental durante la infancia suponen factores de riesgo para diversas patologías físicas y mentales (Repetti, Taylor, y Seeman, 2002), incluyendo ansiedad y depresión (Bifulco, Brown, y Adler, 
1991). Todas estas razones avalan el interés y la importancia que supone el estudio del comportamiento maternal y su sustrato biológico.

Nuestro modelo de estudio para el comportamiento maternal es el ratón. En esta especie, el comportamiento maternal incluye conductas orientadas a las crías (su alimentación, su aseo, su abrigo y agrupación en un nido) y conductas no dirigidas a crías, como son la construcción previa del nido y la defensa de las crías de potenciales amenazas, la llamada «agresión maternal» (Gammie, 2005). De entre estas conductas destaca la agresión maternal por dos motivos. En primer lugar, las madres tienden a agredir a miembros de la misma especie, especialmente a machos, que en la naturaleza suelen ser infanticidas. En segundo lugar, se trata de una conducta transitoria y reversible: las hembras de ratón se ven atraídas por los machos y sus feromonas durante toda su vida (Martínez-García et al., 2009), pero durante el periodo maternal reaccionan agrediéndolos ferozmente si se acercan a su nido (Lonstein y Gammie, 2002). Con el destete de las crías, la agresión se extingue y la hembra vuelve a verse atraída por el macho.

Como otras conductas sociales, el comportamiento maternal, incluida la agresividad, está gobernado por una red compleja de centros nerviosos conocida como el «cerebro sociosexual» (Gammie, 2005; Newman, 1999). Durante este período, para asegurar la expresión de la conducta maternal en el momento oportuno, el cerebro sociosexual sufre una modulación, una maternización. Este proceso aún no se comprende bien, pero debe estar ligado a las señales hormonales de la maternidad (gestación, parto y lactancia), así como a estímulos de las propias crías.

Así pues, la agresión maternal supone una oportunidad para entender el sustrato biológico de la conducta agresiva, y constituye el marco ideal para estudiar los mecanismos responsables de la maternización cerebral. En esta artículo, presentamos una serie de experimentos orientados a entender este fenómeno fascinante. En nuestro primer experimento, empleamos un enfoque conductual para explorar la contribución relativa al proceso de los estímulos de las crías y la señales hormonales de la gestación. A continuación, analizamos con mayor profundidad el papel de una señal endocrina y dos señales neuroquímicas estrechamente ligadas al comportamiento social y a la maternidad, la hormona prolactina y los neuropéptidos oxitocina y vasopresina.

\section{Material y métodos}

\section{Experimento 1. Factores promotores de la agresión maternal en ratones hembra}

En este experimento, empleamos hembras adultas de ratón de la cepa CD1, que distribuimos aleatoriamente en tres grupos experimentales: (i) madres lactantes $(n=9)$, (ii) comadres $(n=9)$ y (iii) hembras vírgenes sin experiencia previa con crías (que llamaremos inexpertas; $\mathrm{n}=9$ ). Las madres lactantes y las hembras inexpertas fueron incluidas como grupos control positivo y negativo, respectivamente, para la conducta agresiva. En cuanto a las comadres, se trata de hembras vírgenes que han sido estabuladas con una hembra del grupo de madres lactantes durante la preñez, parto y lactancia, colaborando en el cuidado de las crías.

Sometimos a estos grupos de hembras a un test de agresión maternal, en el que, tras retirar las crías (en el caso de las madres y las comadres) y la hembra acompañante, se introduce un macho intruso en la caja de la hembra experimental y se evalúa la reacción conductual de la ésta. Los intrusos son machos adultos de la misma cepa y edad. Los encuentros hembraintruso tuvieron una duración de 5 minutos y fueron grabados en vídeo para el posterior registro de las siguientes variables: latencia al primer ataque, número total de ataques y duración 
total de los ataques. Los valores obtenidos fueron análizados (ANOVA o test de Kruskal-Wallis) usando el software SPSS.

\section{Experimento 2. Caracterización del patrón central de respuesta a la prolactina} en ratones hembra y su variación durante gestación y lactancia

Para este estudio, empleamnos 19 hembras de ratón (cepa CD1), de 8-12 semanas de edad, distribuidas aleatoriamente en tres grupos experimentales: vírgenes $(n=7)$; gestación tardía $(n=6)$ y lactantes $(n=6)$. El grupo de vírgenes se procesó directamente para inmunohistoquímica, mientras que las hembras del resto de grupos fueron procesadas, respectivamente, en los días 14 a 18 de gestación (grupo gestación tardía) y en el sexto día postparto (grupo lactancia).

Para la inmunohistoquímica, los animales se perfundieron con paraformaldehido, extrajimos sus encéfalos del cráneo, y los postfijamos y crioprotegimos para obtener secciones histológicas de $40 \mu \mathrm{m}$ con microtomía de congelación. Las secciones histológicas fueron procesadas para la inmunohistoquimica de PSTAT5, un método indirecto para la evaluación de las acciones centrales de la prolactina. Consiste en la detección de la forma activada por fosforilación de STAT5 (PSTAT5), una proteína clave en la cascada de transducción del receptor largo de prolactina (Kanyicska, Lerant, Freeman y Marc, 2000). Disponemos asi de un marcador funcional de aquellas células que han respondido recientemente a la señal de prolactina. Tras la inmunohistoquímica, los cortes histológicos fueron montados y cubiertos para su posterior análisis al microscopio óptico.

\section{Experimento 3. Caracterización del patrón central de expresión de oxitocina en ratones hembra y su colocalizacion con vasopresina}

En el presente estudio, usamos 12 hembras adultas de ratón de la cepa CD1, que procesamos para la inmunohistoquímica de los péptidos como en el experimento anterior. Sin embargo en esta ocasión hicimos una doble inmunofluorescencia ide oxitocina y vasopresina: cada antígeno queda asociado a un fluoróforo, molécula que emitirá fluorescencia en una longitud de onda (un color) específica. La vasopresina quedó asociada al fluoróforo alexa fluor (fluorescencia verde) y la oxitocina a rhodamine red (fluorescencia roja). Una vez concluida la inmunofluorescencia, las secciones histológicas fueron montadas y cubiertas para su análisis mediante microscopia confocal.

\section{Resultados}

\section{Experimento 1. Factores promotores de la agresión maternal en ratones hembra}

El objetivo de este experimento fue evaluar la contribución del contacto con crías en la expresión de agresión de tipo maternal. Comparamos el comportamiento agresivo frente a un macho intruso de madres lactantes, comadres y vírgenes inexpertas. Los resultados, recogidos en la figura 1 , indican que el grupo de madres lactantes ataca significativamente antes ( $p<0,05$; figura 1A), durante más tiempo ( $p<0,001$; figura 1B) y más veces ( $p<0,001$; figura 1C) a los machos de lo que lo hacen las demás hembras. De hecho, los valores medios para el número y la duración de los ataques en los grupos de comadres y vírgenes son virtualmente 
nulos, indicativos de que ninguno de estos dos grupos presenta una conducta agresiva hacia machos intrusos.
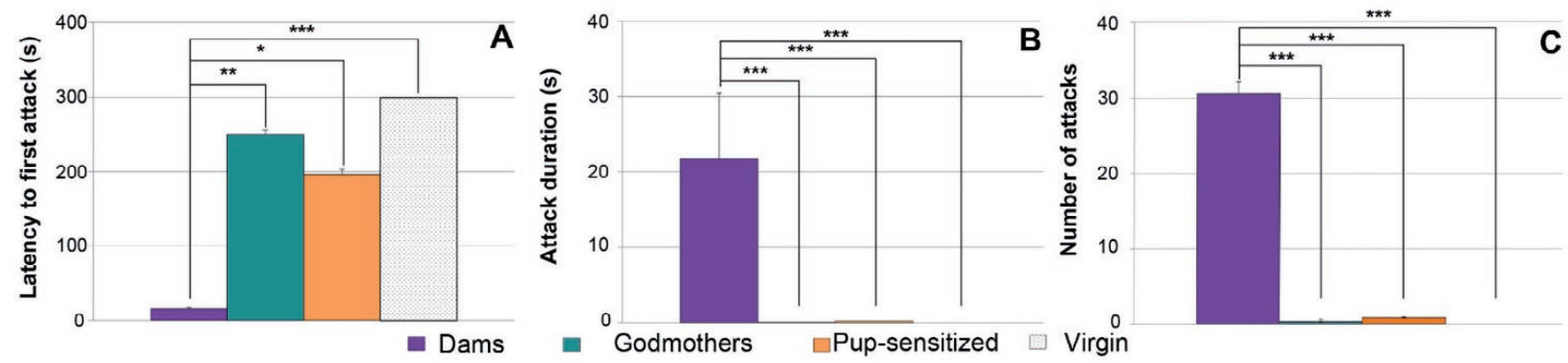

${ }^{*} p<0,05 ;{ }^{* *} p<0,01 ;{ }^{* *} p<0,001$

Figura 1. Agresión maternal de madres lactantes, comadres y vírgenes inexpertas. Representación gráfica de los valores obtenidos (media \pm error estándar de la media) por madres lactantes (morado), comadres (verde), hembras vírgenes sensibilizadas (naranja, grupo no incluido en este artículo) y hembras vírgenes sin contacto con crías (blanco) en la latencia al primer ataque al intruso $(A)$, la duración total de los ataques (B) y el número total de ataques (C). El test de Kruskal-Wallis revela que las madres lactantes atacaron a los machos intrusos

con una latencia sinificativamente menor y una duración y número de ataques significativamente mayores a los demás grupos experimentales, comadres y hembras vírgenes sin contacto con crías, que muestran valores virtualmente nulos de agresión

\section{Experimento 2. Caracterización del patrón central de respuesta a la prolactina en ratones hembra y su variación durante gestación y lactancia}

El análisis de la distribución central de inmunorreactividad para PSTAT5 en hembras vírgenes puso de manifiesto una variabilidad considerable en la presencia y extensión de pSTAT5 (ver figuras $2 \mathrm{~A}$ y $2 \mathrm{~B}$ ), con patrones generalmente moderados pero inconstantes. Por el contrario, las hembras gestantes (segunda mitad dela gestación) muestran un patrón especialmente extenso y con una variabilidad interindividual prácticamente nula. A su vez, el grupo de madres lactantes presentó un patrón virtualmente idéntico e igual de estable que el hallado en el grupo de gestación tardía.

El patrón de inmunorreactividad para pSTAT5 propio de la gestación tardía y lactancia engloba principalmente a centros subcorticales, amigdalinos, hipotalámicos, talámicos, mesencefálicos e incluso a algunos centros localizados en el tronco del encéfalo. Curiosamente, la gran mayoría de estos centros es parte integrante del cerebro sociosexual (ver introducción). Entre ellos, algunos de los ejemplo más destacados son el séptum, la amígdala medial y central, el núcleo de la stria terminalis y su continuo con el área preóptica del hipotálamo (continuo BSTV-MPO, ilustrado en la figura 2), el núcleo ventromedial hipotalámico o el área gris periacueductal. Estos núcleos están implicados de una u otra forma en la gestión del comportamiento maternal. 

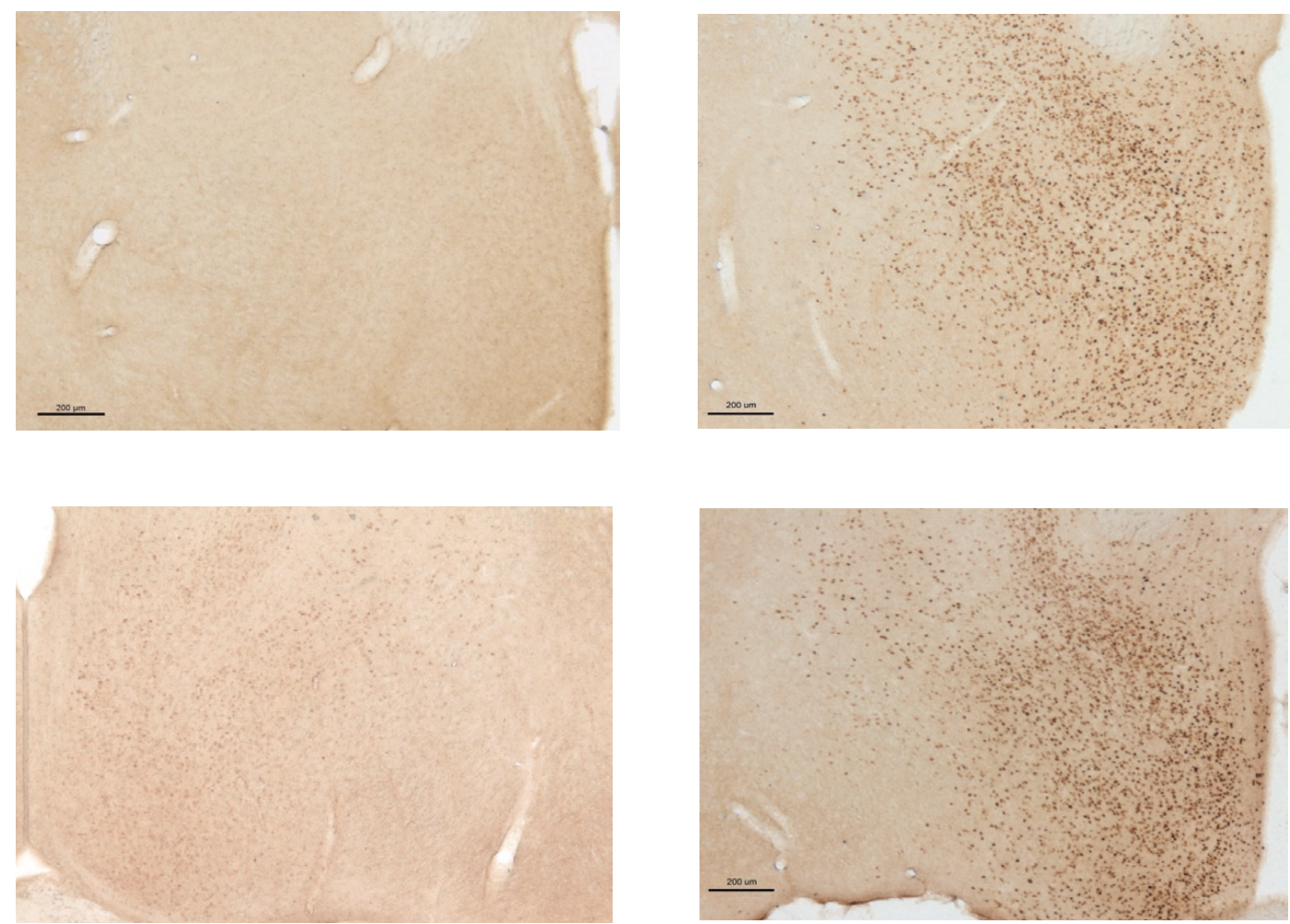

Figura 2. Diferencias en el patrón de respuesta a prolactina en ratones hembra vírgenes, gestantes y lactantes. Patrón de inmunorreactividad para pSTAT5 en la región del continuo BSTV-MPO, nodo del cerebro sociosexual clave en la expresión del comportamiento maternal. Las figuras A y B corresponden a 2 especímenes diferentes del grupo de hembras vírgenes, con un patrón prácticamente ausente $(A)$ y un patrón moderado $(B)$.

La figura $\mathrm{C}$ corresponde a una hembra en el periodo final de gestación y revela un patrón denso y extenso de cuerpos celulares marcados para pSTAT5. El patrón en hembras lactantes (D) es virtualmente idéntico al anterior. Barras de escala: $200 \mu \mathrm{m}$

\section{Experimento 3. Caracterización del patrón central de expresión de oxitocina en ratones hembra y su colocalizacion con vasopresina}

El análisis de los cuerpos celulares positivos para estos neuropéptidos reveló su abundancia en los principales nucleos neurosecretores del hipotálamo: el núcleo paraventricular hipotalámico, el núcleo supraóptico y el núcleo supraquiasmático. Hallamos también una población adicional de células oxitocina-positivas en la región comprendida entre el núcleo de la stria terminalis (BST) y el núcleo preóptico medial del hipotálamo (MPO), el continuo BSTV-MPO. La co-localización de vasopresina y oxitocina está prácticamente restringida a esta población (figura 3), en donde dominan células con expresión elevada de oxitocina y escasa de vasopresina. 

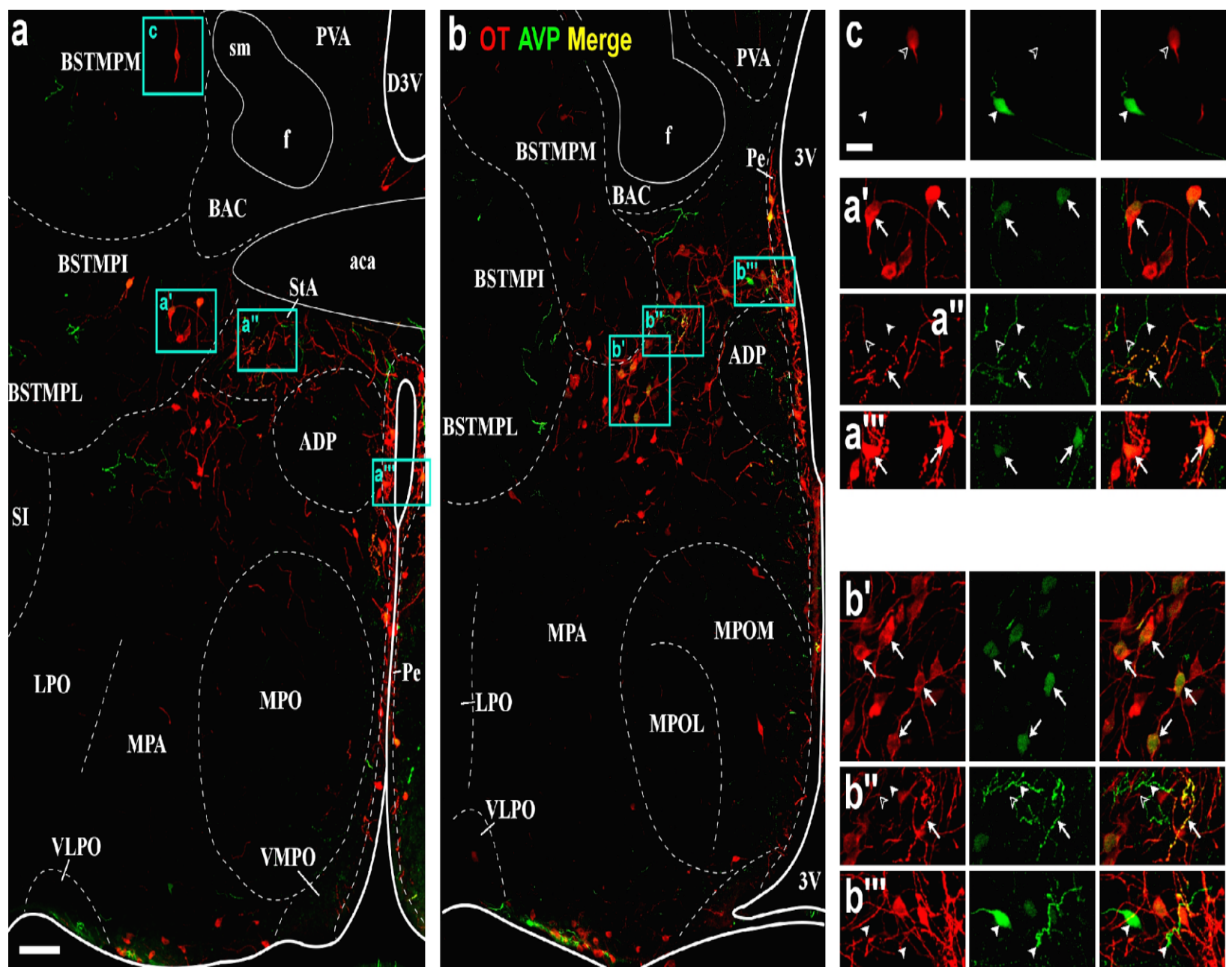

Figura 3. Coexpresión de oxitocina y vasopresina en la región del continuo BSTV - MPO. Fotomicrografías mostrando el resultado de la inmunofluorescencia doble para oxitocina (rojo) y vasopresina (verde) en dos niveles diferentes

$(a, b)$ de la región comprendida entre el aspecto ventral del núcleo de la stria terminalis (BSTV) y el núcleo preóptico medial del hipotálamo (MPO), conocida como el continuo BSTV-MPO. Los detalles enmarcados en $a$ ', a", a"' y en b', b" y b"' muestran varios ejemplos de colocalización de oxitocina y vasopresina.

En el desarrollo de estos marcos (derecha), se muestra el canal que detecta la fluorescencia de oxitocina (columna izquierda), el canal que detecta la fluorescencia de vasopresina (columna central) y la suma de ambos canales (columna derecha), con los puntos de colocalización en una coloración amarillenta (flechas).

Barras de escala en a y $b: 100 \mu \mathrm{m}$.

Con respecto a la distribución de axones marcados, hallamos procesos inmunorreactivos mayoritariamente en los hemisferios cerebrales y el hipotálamo, y excepcionalmente también en algunos núcleos del mesencéfalo y tronco encefálico. La mayoría de estas terminaciones presentaban inmunorreactividad para un único neuropéptido (oxitocina o vasopresina), con la excepción de dos conjuntos específicos donde hallamos colocalización, ubicados en el núcleo central de la amígdala y el núcleo accumbens del estriado, respectivamente. Estas fibras muestran un perfil muy similar al de los cuerpos celulares hallados en el continuo BSTV-MPO antes descritos: niveles altos de oxitocina y bajos de vasopresina. Esta coincidencia sugiere que estas terminaciones se originarían en la población vasopresinérgica/oxitocinérgica del continuo BSTV-MPO. 


\section{Discusión y conclusiones}

\section{Experimento 1. Factores promotores de la agresión maternal en ratones hembra}

El objetivo de nuestro primer experimento fue entender qué factores determinan la inducción de la agresión maternal en hembras de ratón (estímulos derivados de las crías o señales hormonales). Para ello, generamos un modelo experimental muy útil, las comadres. Las comadres, al haber colaborado en el cuidado de las crías, han tenido acceso directo a todos los estímulos generado por éstas, pero no han estado expuestas al entorno hormonal de la gestación y lactancia.

Nuestros resultados (ilustrados en la Figura 1) revelan que las comadres, si bien muestran comportamientos de cuidad de las crías (no ilustrado), no se comportan de forma agresiva frente a machos intrusos que sí que suscitan conducta agresiva en madres lactantes. Los valores medios de su latencia a atacar, la duración y número de ataques a machos intrusos son, de hecho, prácticamente nulos e indistinguibles del grupo de vírgenes inexpertas, el control negativo del experimento. Por consiguiente, la potencial estimulación ejercida por las crías no es suficiente por sí misma para activar una conducta agresiva. Debe, pues, acompañarse de cambios endocrinos o neuroquímicos profundos en el cerebro sociosexual producidos en la gestación y/o la lactancia.

\section{Experimento 2. Caracterizacion del patrón central de respuesta a la prolactina y su variación durante gestación y lactancia}

¿Cuáles son, pues, los eventos endocrinos más notables de este periodo? Uno de los candidatos a los que dirigimos inmediatamente nuestra atención fue la prolactina. Esta hormona es bien conocida (y de hecho recibe su nombre) por su papel director del desarrollo de la glándula mamaria y la producción de leche. Pero sus funciones en el contexto de la maternidad van mucho más allá: la prolactina está implicada en una multitud de procesos de adaptación fisiológica a este periodo, entre los que se encuentra también la regulación del cuidado maternal (Grattan y cols., 2001). Existe evidencia sólida en la rata de que la prolactina es directamente responsable, actuando precisamente sobre el continuo BSTV-MPO, de la expresión del cuidado maternal: la administración focal de prolactina en esta región acelerar la maternización de hembras vírgenes pre-tratadas con progesterona y estradiol (Bridges y Ronsheim, 1990).

Estao sugiere que la prolactina ha de participar también en la gestión de la agresión maternal. Nos propusimos, pues, caracterizar el impacto de esta hormona sobre el cerebro de hembras gestante, en pleno proceso de maternización. Para este cometido, empleamos como indicador la expresión de la proteína PSTAT5 (ver material y métodos). Hallamos un incremento drástico de la inmunorreactividad para PSTAT5 (correlato de la acción de la prolactina) en muchos centros del encéfalo de ratones hembra en el periodo final de su gestación. Este incremento es especialmente evidente en el cerebro sociosexual, afectando al continuo BSTV-MPO (Figura 2) y a otros centros clave en la gestión del comportamiento maternal, de conductas agresivas (septum, núcleo ventromedial hipotalámico; Lin y cols., 2011; Scotti, Lee, y Gammie, 2011) o defensivas (área gris periacueductal, Vianna y Brandão, 2003), o del componente emocional de la conducta social (amígdala, Janak y Tye, 2015). Nuestros resultados confirman, pues, el papel crucial de la prolactina en la maternización del cerebro y apoyan su participación en el desarrollo de la agresión maternal. 


\section{Experimento 3. Caracterización del patrón central de expresión de oxitocina en ratones hembra y su colocalizacion con vasopresina}

Otro elemento digno de estudio en este contexto son los nonapéptidos vasopresina y oxitocina. Existe un vasto cuerpo de evidencia que relaciona estos neuropéptidos con toda clase de comportamientos sociales y afiliativos (Donaldson y Young, 2008). De hecho, en ratas se sabe que los circuitos cerebrales nonapeptidérgicos ejercen un papel clave en la agresión maternal (Bosch, 2013). La información sobre estos péptidos de la que se dispone actualmente en el ratón es escasa y fragmentaria, por lo que nos propusimos caracterizar su distribución y colocalizacion en el encéfalo de ratones hembra, empleando para ello una inmunofluorescencia doble.

Además de las principales poblaciones celulares neurosecretoras (localizadas en los núcleos paraventricular hipotalámico, supraóptico y supraquiasmático), hallamos una población de células que coexpresa ambos neuropéptidos (oxitocina en mayor proporción y vasopresina en menor), y se localiza curiosamente en la región del continuo BSTV-MPO. Como antes avanzábamos, el continuo BSTV-MPO es un nodo clave en el circuito que regula el cuidado maternal, hasta el punto de que en ratas, lesiones de este área suprimen por completo toda atención a las crías (Kalinichev, Rosenblatt, y Morrell, 2000). Por ello, creemos que estas células son las responsables del efecto modulador de oxitocina y vasopresina en las conductas maternales.

En el análisis de los axonales inmunorreactivos, identificamos dos regiones cerebrales donde los axones marcados presentaban un perfil similar de coexpresión (oxitocina en mayor proporción y vasopresina en menor) al de las células del continuo BSTV-MPO, sugiriendo que su origen se encuentra precisamente en ésta población nonapeptidérgica. Estas áreas de proyeccion son el núcleo central de la amígdala y el núcleo accumbens del cuerpo estriado. La primera, como parte de la amígdala, está implicada en la gestión de conductas con elevada carga emocional, como pueden ser respuestas de miedo o ansiedad a estímulos amenazantes (LeDoux, Iwata, Cicchetti, y Reis, 1988). La oxitocina estaría inhibiendo este tipo de respuestas, haciendo a la madre capaz de afrontar la defensa de sus crías frente a amenazas importantes (Bosch, 2013; Knobloch y cols., 2012). La segunda, el núcleo accumbens, forma parte de los circuitos de la recompensa y sería responsable de atribuir un valor reforzante a las crías y, en consecuencia, motivar a la madre a su cuidado (Numan y Woodside, 2010). Estos resultados proporcionan un marco anatómico en el que estudiar las acciones de la oxitocina y vasopresina sobre el comportamiento maternal. Nuestro siguiente paso en esta línea será explorar posibles cambios en la dinámica de vasopresina y oxitocina producidos en esta población durante la gestación.

\section{Conclusión general}

Los trabajos presentados aquí exploran, desde múltiples ángulos, el sustrato biológico de la regulación del comportamiento maternal, en particular de la agresión maternal. Hemos comprobado que las señales hormonales y neuroquímicas son un factor clave en el desarrollo del comportamiento maternal. En particular, la hormona prolactina y los neuropéptidos vasopresina y oxitocina tienen un papel destacado en el proceso. La primera ejerce una activación a gran escala del cerebro sociosexual al completo, las segundas parecen ser neurotransmisores en circuitos implicados en la gestión del comportamiento maternal.

En el futuro, pretendemos caracterizar en detalle el papel de estos mediadores con la perspectiva de lograr la manipulación artificial de la agresión maternal. 


\section{Referencias bibliográficas}

Bifulco, A., Brown, G. W., y Adler, Z. (1991). Early sexual abuse and clinical depression in adult life. The British Journal of Psychiatry, 159, 115-22.

Bosch, O. J. (2013). Maternal aggression in rodents: brain oxytocin and vasopressin mediate pup defence. Philosophical Transactions of the Royal Society of London. Series B, Biological Sciences, 368, 20130085. doi:10.1098/rstb.2013.0085.

Bridges, R. S., y Ronsheim, P. M. (1990). Prolactin (PRL) regulation of maternal behavior in rats: bromocriptine treatment delays and PRL promotes the rapid onset of behavior. Endocrinology, 126, 837-48.

Donaldson, Z. R., y Young, L. J. (2008). Oxytocin, vasopressin, and the neurogenetics of sociality. Science, 322, 900-4.

Gammie, S. C. (2005). Current models and future directions for understanding the neural circuitries of maternal behaviors in rodents. Behavioral and Cognitive Neuroscience Reviews, 4, 119-135.

Grattan, D. R., Pi, X. J., Andrews, Z. B., Augustine, R. A., Kokay, I. C., Summerfield, M. R., ... Bunn, S. J. (2001). Prolactin receptors in the brain during pregnancy and lactation: implications for behavior. Hormones and Behavior, 40, 115-124.

Janak, P. H., y Tye, K. M. (2015). From circuits to behaviour in the amygdala. Nature, 517, 284-292.

Kalinichev, M., Rosenblatt, J. S., y Morrell, J. I. (2000). The medial preoptic area, necessary for adult maternal behavior in rats, is only partially established as a component of the neural circuit that supports maternal behavior in juvenile rats. Behavioral Neuroscience, 114, 196-210.

Kanyicska, L. A., Lerant, A., Freeman, M. E., y Marc, E. (2000). Prolactin: Structure, function and regulation of secretion. Molecular Biology, 80, 1523-1632.

Knobloch, H. S., Charlet, A., Hoffmann, L., Eliava, M., Khrulev, S., Cetin, A. H., ... Grinevich, V. (2012). Evoked axonal oxytocin release in the central amygdala attenuates fear response. Neuron, 73, 553-566. doi:10.1016/j.neuron.2011.11.030.

LeDoux, J. E., Iwata, J., Cicchetti, P., y Reis, D. J. (1988). Different projections of the central amygdaloid nucleus mediate autonomic and behavioral correlates of conditioned fear. The Journal of Neuroscience, 8, 2517-2529.

Lin, D., Boyle, M. P., Dollar, P., Lee, H., Lein, E. S., Perona, P., y Anderson, D. J. (2011). Functional identification of an aggression locus in the mouse hypothalamus. Nature, 470, 221-226.

Lonstein, J. S., y Gammie, S. C. (2002). Sensory, hormonal, and neural control of maternal aggression in laboratory rodents. Neuroscience and Biobehavioral Reviews, 26, 869888.

Martínez-García, F., Martínez-Ricós, J., Agustín-Pavón, C., Martínez-Hernández, J., Novejarque, A., y Lanuza, E. (2009). Refining the dual olfactory hypothesis: pheromone reward and odour experience. Behavioral Brain Research, 200, 277-86.

Meaney, M. J. (2001). Maternal care, gene expression, and the transmission of individual differences in stress reactivity across generations. Annual Review of Neuroscience, 24, 1161 92.

Newman, S. W. (1999). The medial extended amygdala in male reproductive behavior. A node in the mammalian social behavior network. Annals of the New York Academy of Sciences, 877, 242-257.

Numan, M., e Insel, T. R. (2003). The neurobiology of parental behavior. Nueva York: Springer. 
Numan, M., y Woodside, B. (2010). Maternity: neural mechanisms, motivational processes, and physiological adaptations. Behavioral Neuroscience, 124, 715-41.

Repetti, R. L., Taylor, S. E., y Seeman, T. E. (2002). Risky families: family social environments and the mental and physical health of offspring. Psychological Bulletin, 128, 330-66.

Scotti, M.-A. L., Lee, G., y Gammie, S. C. (2011). Maternal defense is modulated by beta adrenergic receptors in lateral septum in mice. Behavioral Neuroscience, 125, 434-45.

Vianna, D. M. L., y Brandão, M. L. (2003). Anatomical connections of the periaqueductal gray: Specific neural substrates for different kinds of fear. Brazilian Journal of Medical and Biological Research, 36, 557-566. 